\title{
Locally advanced breast implant-associated anaplastic large-cell lymphoma: a case report of successful treatment with radiation and chemotherapy
}

\author{
Christopher F. Estes ${ }^{1}$ *, Da Zhang ${ }^{2}$, Ruben Reyes ${ }^{3}$, Richard Korentager $^{4}$, Marilee McGinness $^{5}$ and \\ Christopher Lominska
}

${ }^{1}$ Department of Radiation Oncology, University of Kansas Medical Center, Kansas City, KS, USA

2 Department of Pathology, University of Kansas Medical Center, Kansas City, KS, USA

${ }^{3}$ Department of Hematology, University of Kansas Medical Center, Kansas City, KS, USA

${ }^{4}$ Department of Plastic Surgery, University of Kansas Medical Center, Kansas City, KS, USA

${ }^{5}$ Department of Breast Surgery, University of Kansas Medical Center, Kansas City, KS, USA

\section{Edited by:}

Brian Timothy Collins, Georgetown

Hospital, USA

\section{Reviewed by:}

Kathryn Huber, Tufts Medical Center, USA

Heath Brandon Mackley, Penn State Hershey Cancer Institute, USA

*Correspondence:

Christopher F. Estes, Department of Radiation Oncology, University of

Kansas Medical Center, 3901

Rainbow Boulevard, Kansas City, KS

66160, USA

e-mail: cestes3@kumc.edu
The development of breast implant-associated anaplastic large-cell lymphoma ( $A L C L$ ) is a rare phenomenon. A typical presentation is an effusion associated with a breast implant. Less commonly, disease can be more advanced locoregionally or distantly. The optimal treatment schema is a topic of debate: localized ALCL can potentially be cured with implant removal alone, while other cases in the literature, including those that are more advanced, have been treated with varying combinations of surgery, chemotherapy, and external beam radiotherapy. This is a case report of breast implant ALCL with pathologically proven lymph node involvement, the fifth such patient reported. Our patient experienced a favorable outcome with radiation therapy and chemotherapy.

Keywords: breast implant-associated anaplastic large-cell lymphoma, breast, breast implant, non-Hodgkin lymphoma, radiation therapy, chemotherapy

\section{INTRODUCTION}

A 76-year-old Caucasian woman was found to have implantassociated anaplastic lymphoma with pathologically proven nodal involvement and was successfully treated by implant removal, chemotherapy, and radiotherapy. She had gel breast implantation performed 20 years prior to presentation. These were later replaced by saline implants. One year before presentation the saline implants were leaked and replaced with gel implants. She developed a recurrent fluid collection involving her right breast (Figure 1). A drain was placed and yielded minimal output before being removed 1 week later. Cytology of the fluid demonstrated atypical appearing lymphocytes. The fluid later reaccumulated, and right axillary lymphadenopathy was noted on physical exam (largest node $5.1 \mathrm{~cm}$ on ultrasound). Core needle biopsy of the node revealed rare atypical cells.

She underwent capsulectomy and right axillary nodal excisional biopsy with bilateral implant removal in 2011. On histopathologic analysis, anaplastic large-cell lymphoma (ALCL), anaplastic lymphoma kinase (ALK)-negative was demonstrated in the fibrous capsule, cystic fluid, and axillary lymph nodes (Figures $\mathbf{2}$ and $\mathbf{3}$ ). Imaging with $\mathrm{CT}$ and PET scans demonstrated residual right axillary lymphadenopathy with FDG avidity, as illustrated in Figure 4. Bone marrow analysis was performed and showed no evidence of lymphoma involvement. The patient was staged as Ann Arbor stage IIE. She was treated with six cycles of cyclophosphamide $750 \mathrm{mg} / \mathrm{m}^{2}$, doxorubicin $50 \mathrm{mg} / \mathrm{m}^{2}$, vincristine $2 \mathrm{mg}$, and prednisone. Prednisone required a dose reduction from 100 to $75 \mathrm{mg}$ after the first cycle to minimize hyperglycemia secondary to diabetes mellitus type II. Pegfilgrastim $6 \mathrm{mg}$ was injected each cycle for hematopoietic support. Ciprofloxacin $500 \mathrm{mg}$ BID was used daily for bacterial infection prophylaxis. After cycle 2, she began to display adverse effects of nausea grade 2 , oral mucositis grade 1 , and dysgeusia grade 2 per National Cancer Institute Common Terminology Criteria for Adverse Events grading scale version 4.03 (1). Tetrahydrocannabinol was administered for treatment of nausea and anorexia. Weight loss of grade 1 occurred by the end of therapy. Interval PET and CT imaging were performed after cycle 2 , demonstrating metabolic activity of SUV 0.88 in the right axillary lymph nodes, a partial response. Repeat PET imaging was performed after cycle 4 of chemotherapy, confirming complete response to treatment.

Adjuvant radiation therapy was then delivered to the right breast, axilla, and right supraclavicular nodes to $30.6 \mathrm{~Gy}$ in $1.80 \mathrm{~Gy}$ fractions, finishing in January of 2012. A monoisocentric technique was used with breast tangents matched to a field covering the supraclavicular nodes and high axilla. The axilla levels $1-3$ were contoured and a lightly weighted posterior axillary field was used to bring the volume up to the prescription dose (Figure 5). With therapy, the patient experienced grade 1 dermatitis manifested as faint erythema within the treatment field. Two-year follow-up with PET imaging and clinical evaluation showed no evidence of disease. The patient wished to have breast augmentation again. She underwent silicone gel implant placement bilaterally and has been followed for an additional year without evidence of disease. 


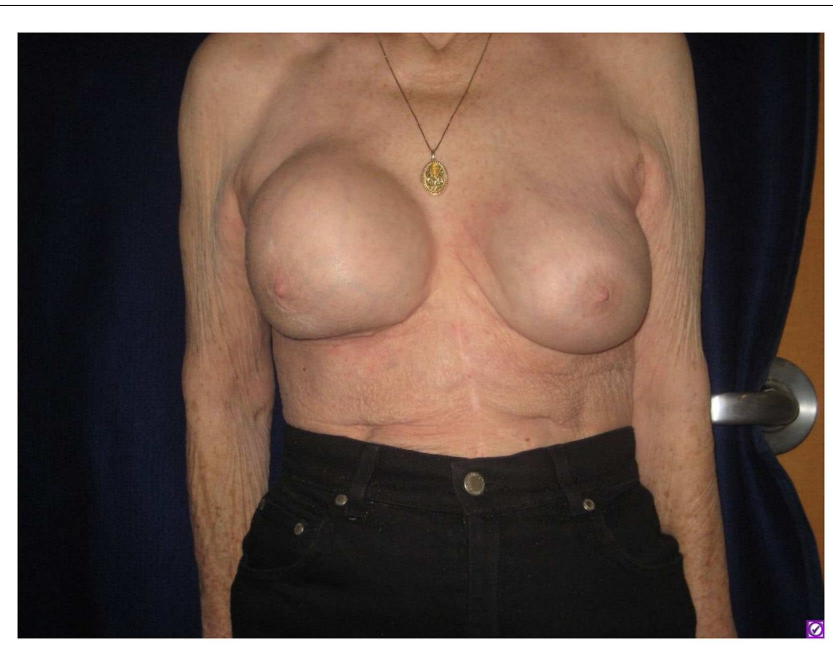

FIGURE 1 | Firmness and marked increase in size of the right breast as seen on presenting physical examination.

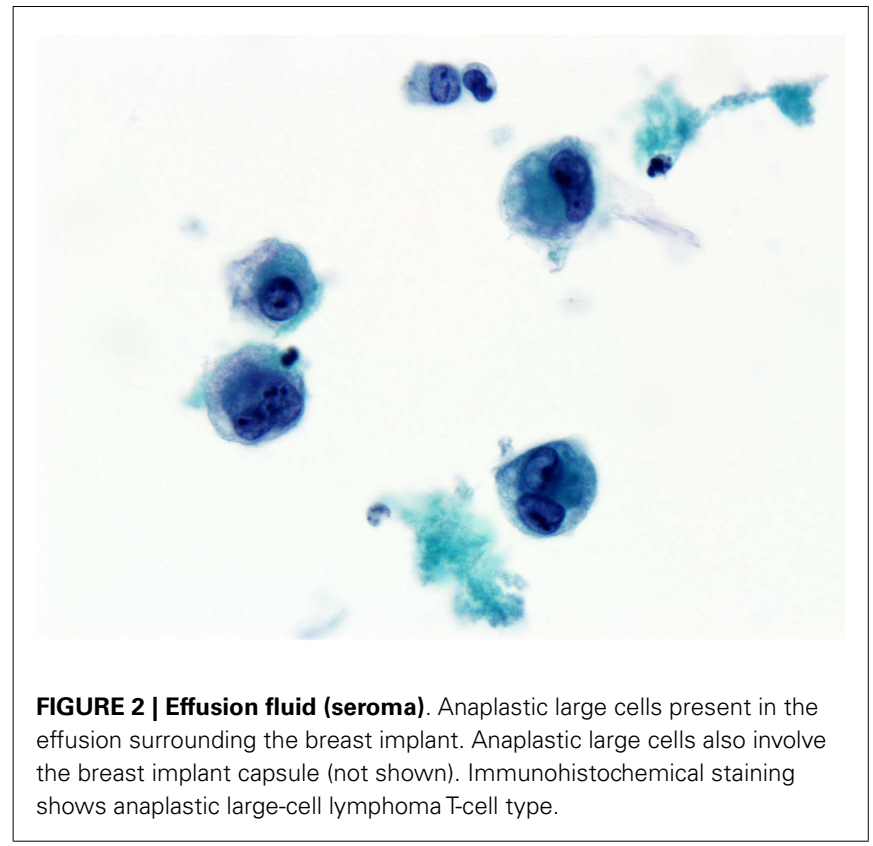

\section{BACKGROUND}

Primary breast lymphomas represent about $0.1-0.5 \%$ of total breast tumors, and approximately $3 \%$ of non-Hodgkin lymphomas of extranodal sites (2). Tumors of ALCL histology represent $2 \%$ of adult non-Hodgkin lymphomas and are the second most common peripheral T cell lymphoma $(3,4)$. The entity of breast implant-associated ALCL was first described by Keech and Creech (5) in 1997, and currently at least 60 cases have been described in the literature (6). A study in the Netherlands estimated that the incidence of breast implant-associated ALCL is 1 out of 500,000 per woman with prostheses per year, using a casecontrol model with breast lymphomas other than ALCL as the control (7). However, there has been controversy regarding the

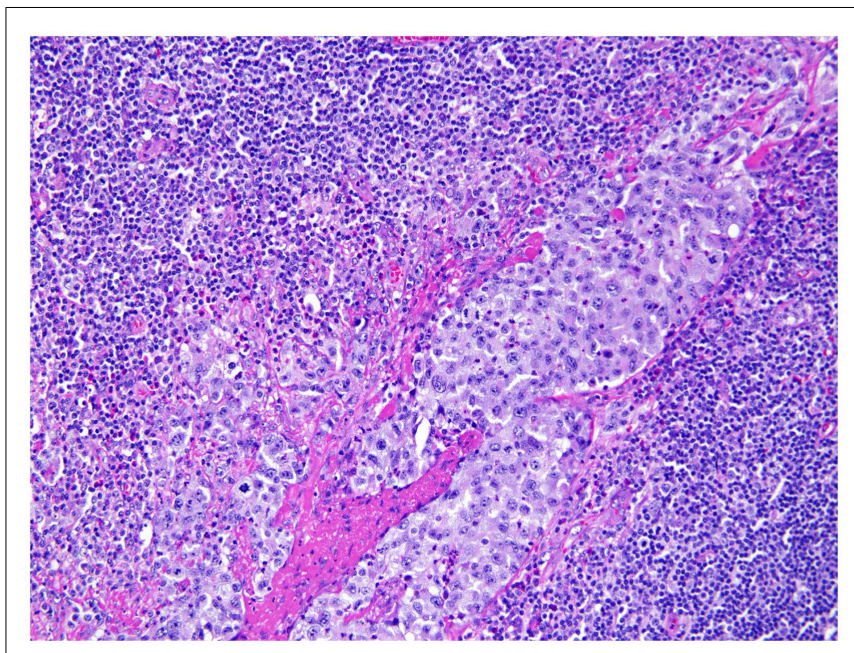

FIGURE 3 | Axillary lymph node. Axillary lymph node of the same patient shows large atypical cells involving the sinusoidal and lymphatic space, consistent with anaplastic large cells involving the lymph node.

level of risk associated with breast prosthesis implantation (8). The FDA reports that 5-10 million women have undergone breast implantation, leading to a possible estimation of breast-associated ALCL incidence of $1: 80,000$ to $1: 170,000$ given the 60 reported cases thus far (9).

Morphologically, ALCL is composed of large blastic cells with pleomorphic, often horseshoe-shaped or multiple nuclei. Growth is in a cohesive pattern often involving lymph node sinuses with a variable composition of granulocytes and macrophages. In breastassociated and cutaneous ALCL, the cells are CD30 positive on cytogenetic studies and negative for ALK (10). In contrast, systemic ALCL is characterized by positive ALK (11). Those who present with a mass rather than an effusion have a higher risk of failure or relapse (12). Various treatment regimens have been employed including surgery (implant removal) followed by observation, chemotherapy alone, chemotherapy and radiation, and radiation alone. Patients who present with disease limited to an effusion surrounding the fibrous capsule surrounding the implant have been shown to have a favorable outcome with observation; however, there are rare cases of advanced and treatment-resistant disease leading to fatality (13). The ideal treatment schema is yet to be elucidated.

We report a locally advanced case of breast implant-associated ALCL at our institution. Pathologic axillary nodal involvement by breast implant-associated ALCL is rare: only four cases of pathologically confirmed disease of the axillary nodes have been described. Of the 60 cases reported, workup for axillary nodal involvement was carried out in 29, 10 of which were found to have clinical evidence of axillary lymphadenopathy. Four of these were confirmed pathologically (6); our patient represents the fifth.

\section{DISCUSSION}

Treatment methods in breast implant-associated ALCL have included surgery, radiation therapy, chemotherapy, their various combinations, and observation. Overall survival is typically 

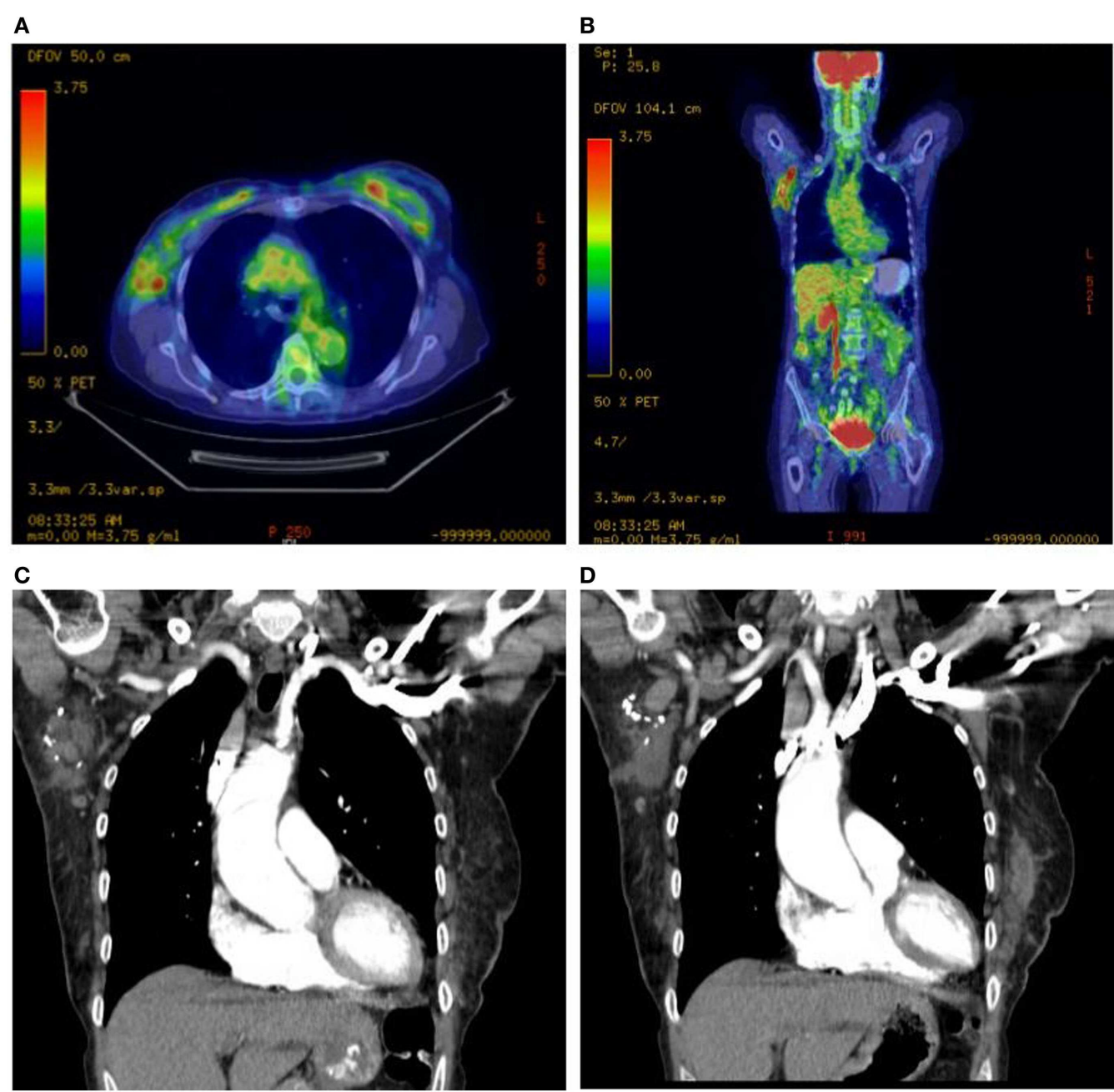

FIGURE 4 | Right axillary lymphadenopathy demonstrated on axial and coronal PET scan images with abnormal FDG avidity (A,B) and coronal CT images with contrast (C,D)

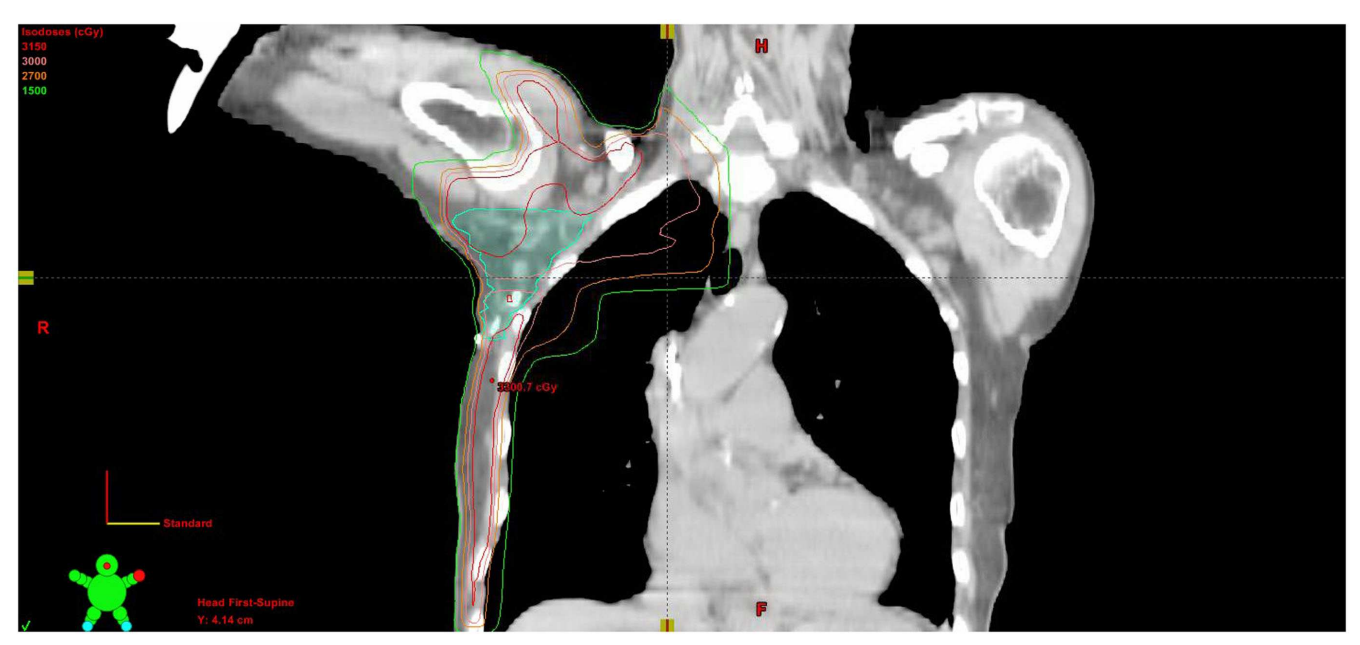

FIGURE 5 | Coronal CT slice of treatment plan showing isodose lines and contoured axillary nodal volume. 
favorable, and only three patients have been reported to die of disease. ALCL can also present in a systemic or cutaneous manner. Systemic disease is typically more aggressive; those with cutaneous lymphomas carry a more favorable prognosis and negative ALK, similar to breast ALCL (14). On long-term follow-up of the 60 patients reported by Miranda et al., patients who were found to have disease confined to the fibrous capsule experienced improved complete response, overall survival, and progressionfree survival. Those treated with chemotherapy alone did not experience improved outcome compared to those treated with either watchful waiting or radiotherapy alone. The four patients who received radiotherapy alone are free from recurrence (6).

Patients who present with effusion confined disease have had long-term relapse free intervals with observation alone. Those with a mass show a more aggressive prognosis, and may achieve a greater benefit with combined modality therapy with chemotherapy and radiation. Implant removal in ALCL is recommended: in one review, three of four patients without implant removal relapsed, all of whom responded to salvage therapy (12). More aggressive tumors may arise in those patients with prior breast cancer (15).

\section{CONCLUDING REMARKS}

For the advanced presentation of axillary nodal involvement in our patient, we obtained a favorable outcome with combined modality treatment with radiation therapy and chemotherapy. Our patient chose to undergo placement of new implants after her treatment. It was discussed with the patient that the risks of implant replacement after treatment are unknown in this setting. She chose to proceed and has had no adverse consequence to date. Finally, this clinical scenario highlights the importance of regional nodal evaluation in patients with breast implant ALCL.

\section{REFERENCES}

1. National Cancer Institute. Common Terminology Criteria for Adverse Events. Washington, DC: National institute of health (2010).

2. Vasei M, Kumar PV, Malekhosseini SA, Amirghofran Z. Primary T-cell lymphoma of the breast with lymphoepithelial lesion. A case report. APMIS (1997) 105(6):445-8. doi:10.1111/j.1699-0463.1997.tb00592.x

3. Armitage JO, Weisenburger DD. New approach to classifying non-Hodgkin's lymphomas: clinical features of the major histologic subtypes. non-Hodgkin's lymphoma classification project. J Clin Oncol (1998) 16(8):2780-95.

4. Wang S, Vose J. Epidemiology and prognosis of T-cell lymphoma. In: Foss F, editor. T-Cell Lymphomas. New York, NY: Springer Science+Business Media (2013). 25 p.

5. Keech JA Jr, Creech BJ. Anaplastic T-cell lymphoma in proximity to a saline-filled breast implant. Plast Reconstr Surg (1997) 100(2):554-5.
6. Miranda RN, Aladily TN, Prince HM, Kanagal-Shamanna R, de Jong D, Fayad LE, et al. Breast implant-associated anaplastic large-cell lymphoma: long-term follow-up of 60 patients. J Clin Oncol (2014) 32(2):114-20. doi:10.1200/JCO. 2013.52.7911

7. de Jong D, Vasmel WL, de Boer JP, Verhave G, Barbe E, Casparie MK, et al. Anaplastic large-cell lymphoma in women with breast implants. JAMA (2008) 300(17):2030-5. doi:10.1001/jama.2008.585

8. Lipworth L, Tarone RE, McLaughlin JK. Breast implants and lymphoma risk: a review of the epidemiologic evidence through 2008. Plast Reconstr Surg (2009) 123(3):790-3. doi:10.1097/PRS.0b013e318199edeb

9. FDA. FDA Medical Device Safety Communication: Reports of Anaplastic Large Cell Lymphoma (ALCL) in Women with Breast Implants. (2011). Available from: http://www.fda.gov/\%20medicaldevices/safety/alertsandnotices/ ucm 240000.htm

10. Aladily TN, Medeiros LJ, Amin MB, Haideri N, Ye D, Azevedo SJ, et al. Anaplastic large cell lymphoma associated with breast implants: a report of 13 cases. Am J Surg Pathol (2012) 36(7):1000-8. doi:10.1097/PAS.0b013e31825749b1

11. Stein H, Foss HD, Durkop H, Marafioti T, Delsol G, Pulford K, et al. CD30(+) anaplastic large cell lymphoma: a review of its histopathologic, genetic, and clinical features. Blood (2000) 96(12):3681-95.

12. Thompson PA, Prince HM. Breast implant-associated anaplastic large cell lymphoma: a systematic review of the literature and mini-meta analysis. Curr Hematol Malig Rep (2013) 8(3):196-210. doi:10.1007/s11899-013-0164-3

13. Carty MJ, Pribaz JJ, Antin JH, Volpicelli ER, Toomey CE, Farkash EA, et al. A patient death attributable to implant-related primary anaplastic large cell lymphoma of the breast. Plast Reconstr Surg (2011) 128(3):112e-8e. doi:10.1097/ PRS.0b013e318221db96

14. Kim B, Roth C, Chung KC, Young VL, van Busum K, Schnyer C, et al. Anaplastic large cell lymphoma and breast implants: a systematic review. Plast Reconstr Surg (2011) 127(6):2141-50. doi:10.1097/PRS.0b013e3182172418

15. George EV, Pharm J, Houston C, Al-Quran S, Brian G, Dong H, et al. Breast implant-associated ALK-negative anaplastic large cell lymphoma: a case report and discussion of possible pathogenesis. Int J Clin Exp Pathol (2013) 6(8):1631-42.

Conflict of Interest Statement: The authors declare that the research was conducted in the absence of any commercial or financial relationships that could be construed as a potential conflict of interest.

Received: 02 December 2014; paper pending published: 05 January 2015; accepted: 23 January 2015; published online: 18 February 2015.

Citation: Estes CF, Zhang D, Reyes R, Korentager R, McGinness $M$ and Lominska $C$ (2015) Locally advanced breast implant-associated anaplastic large-cell lymphoma: a case report of successful treatment with radiation and chemotherapy. Front. Oncol. 5:26. doi: 10.3389/fonc.2015.00026

This article was submitted to Radiation Oncology, a section of the journal Frontiers in Oncology.

Copyright (c) 2015 Estes, Zhang, Reyes, Korentager, McGinness and Lominska. This is an open-access article distributed under the terms of the Creative Commons Attribution License (CC BY). The use, distribution or reproduction in other forums is permitted, provided the original author(s) or licensor are credited and that the original publication in this journal is cited, in accordance with accepted academic practice. No use, distribution or reproduction is permitted which does not comply with these terms. 